\title{
Visual marking: A convergence of goal- and stimulus-driven processes during visual search
}

\author{
PAUL ATCHLEY, SYBIL E. JONES, and LESA HOFFMAN \\ University of Kansas, Lawrence, Kansas
}

\begin{abstract}
Watson and Humphreys (1997) proposed that visual marking is a goal-directed process that enhances visual search through the inhibition of old objects. In addition to the standard marking case with targets at new locations, included in Experiment 1 was a set of trials with targets always at old locations, as well as a set of trials with targets varying between new and old locations. The participants' performance when detecting the target at old locations was equivalent to their performance in the full-baseline condition when they knew the target would be at old locations, and was worse when the target appeared at old locations on $50 \%$ of the trials. Marking was observed when the target appeared at new locations. In Experiment 2, an offset paradigm was used to eliminate the influence of the salient abrupt-onset feature of the new objects. No significant benefits were found for targets at new locations in the absence of onsets at new locations. The results suggest that visual marking may be an attentional selection mechanism that significantly benefits visual search when (1) the observer has an appropriate search goal, (2) the goal necessitates inhibition of old objects, and (3) the new objects include a salient perceptual feature.
\end{abstract}

People routinely search through complex visual environments, as when looking up a number in the phone book, navigating through unfamiliar streets using a map, or watching a sporting event. People look for road signs, classified ads, sunglasses, earrings, car keys, and so forth. Usually, familiar objects are sought and found promptly in their expected locations. When a noticeable object (e.g., a gallon of milk) is located in an expected location (e.g., the refrigerator), cognitive processes involved in differentiating that object from others in the visual environment seem deceptively simple. Yet at other times, objects are found in their expected locations only after a tedious, effortful search. For example, trying to find a four-leaf clover can be a frustrating experience, even when it is located in an expected location (e.g., a patch of clover). The examples above illustrate a combination of two factors that can influence selective attention in visual search: top-down, goalrelevant expectations regarding likely target locations, and bottom-up, feature-dependent similarities and differences between the targets and their potential distractors. When distractors and targets have many of the same features and

This research was supported by a University of Kansas General Research Fund grant to P.A. and by a University of Kansas Undergraduate Research Award to S.E.J. We thank Todd Horowitz, Derrick Watson, and an anonymous reviewer for their discerning observations and helpful suggestions. The data were also presented at the 41 st Annual Meeting of the Psychonomic Society, New Orleans, November 2000. Correspondence pertaining to this article may be addressed to P. Atchley, Department of Psychology, University of Kansas, 426 Fraser Hall, Lawrence, KS 66045-2160 (e-mail: patchley@ku.edu). no information is available to reduce the uncertainty about the target's location, visual search becomes increasingly difficult. Recently, a mechanism of selective attentionvisualmarking — was introduced to account for the increased efficiency observed when the most likely target locations receive priority during visual search.

Visual marking, as described by Watson and Humphreys (1997, 1998, 2000; see also Kahneman, Treisman, \& Burkell, 1983; Theeuwes, Kramer, \& Atchley, 1998), is a goal-directed, top-down attentional mechanism that aids visual search by deprioritizing or inhibiting, in a spatially parallel manner, the location, color, form, or motion of previously presented objects. Visual marking has been observed in visual search tasks when it is known that the target will never be presented at an "old" location. When new objects are added to a visual scene, they take priority during search, because old objects are "marked" for nonsearch, given that they are always distractors. The present work addresses a critical component of this suggestion. To what extent is visual marking a goal-directed, voluntary process of deprioritizing goal-irrelevant, old objects before the new, target-relevant set of objects is presented? Alternatively, to what extent can marking be accounted for by automatic processes that lead to stimulus-driven prioritization of new objects for search, without requiring intentional deprioritization of old objects?

In their initial study of visual marking, Watson and Humphreys (1997) used a conjunction search task, although in later work other types of search tasks have been used as well (see Kramer \& Atchley, 2000; Watson \& Humphreys, 2000). In the standard marking paradigm, each trial con- 
tains a two-stage display sequence known as the gap condition. First, a group of distractor objects (referred to as old objects) is displayed for a fixed amount of time-typically, 400 to $1,000 \mathrm{msec}$. Then a group of new objectsthe target and the remaining distractors-is added to the display. Observers are instructed to wait until after the second group of objects appears to start their search, because the target, when present, will always appear with these new objects. The gold standard of marking is the degree to which search times (as measured by search slopes, search speed, or both) are similar in the gap condition to a half-baseline condition, in which observers search only half the total number of objects in the gap condition. In other words, if observers perfectly mark the old objects (i.e., objects presented before the temporal gap) for nonsearch, then only the number of new objects (objects presented after the temporal gap) should influence their search times. Marking has been shown to work with static as well as moving displays (Watson \& Humphreys, 1998). Also, the presence of a simple feature difference between old and new displays does not seem to be a requirement of marking (Watson, 2001), although temporal grouping does appear to be critical (Jiang, Chun, \& Marks, 2002b).

The extent to which visual marking can be considered a goal-directed deprioritization of old objects is a matter of debate. An alternative explanation is that the benefit in search speed for a target presented with the new objects could have resulted automatically via a salient perceptual change in luminance, rather than as the result of a goaldirected deprioritization of objects at old locations. In two of Watson and Humphreys's (1997) original experiments, abrupt-onset presentation of new objects after the gap was synchronized with the addition (Experiment $4 a$ ) or deletion (Experiment 5) of line segments from the old objects. When the old objects were modified as the new objects were presented, no evidence of visual marking was observed. If salient perceptual changes (luminance increments or decrements) automatically capture attention, or if visual marking is involuntarily interrupted when detectable changes occur at old locations at the same time that new potential target objects are added to the display, ostensibly, search would encompass all of the objects (Watson \& Humphreys, 1997). Congruently, Donk and Theeuwes (2001) reported that when new objects were equiluminant to the background, thereby removing the possibility of prioritization on the basis of a change in luminance, visual marking did not occur. This led the authors to suggest that, rather than being the result of deprioritization of old objects, visual marking might be the result of the prioritization of new objects. Consider a search among 30 objects ( 15 old and 15 new) in comparison with a half-baseline search among 15 new objects. In both cases, if attentional priority is set for new objects, then search is among 15 objects. Deprioritization of old locations is not necessary to account for the marking data.

Watson and Humphreys (2000) have presented additional evidence to support their claim that deprioritization does occur at old locations. In their first experiment, they presented dot probes in $24 \%$ of the trials. During the probe trials (identified by a tone presented simultaneously with the search display), participants were asked to respond to the presence or absence of a probe dot and to assign a confidence rating to their responses. Probes were more difficult to detect at old object locations during visual search when the participants expected the target to be among the new objects. Their results suggest that there was inhibition of distractors at old locations, as well as that visual marking is a voluntary mechanism.

Together, these previous studies suggest that visual marking is an attentional selection mechanism that benefits visual search when (1) the observer has accurate, targetrelevant information and uses it to adopt an appropriate goal state, (2) the appropriate goal necessitates inhibition of old objects (or prioritization of new objects), and (3) the new objects have in common a salient perceptual feature that can engage automatic selection processes complementary to the observer's goal state. Therefore, to understand visual marking, one must consider both voluntary, goal-relevant inhibitory processes acting on the old objects and complementary stimulus-driven processes dependent on features of the new objects.

Another potential factor in the efficiency of visual marking is the extent to which marking effects are influenced by goal-relevant, top-down expectations of stimulus features, such as abrupt onset (see, e.g., Folk, Remington, $\&$ Johnston, 1992). For example, whereas most research results support the notion that abrupt onsets of new objects are capable of attracting attention in a stimulus-driven fashion (Jonides \& Yantis, 1988; Yantis \& Jonides, 1984), there is also evidence that attentional orienting toward goal-relevant changes in luminance is enhanced by goaldirected processes (Atchley, Kramer, \& Hillstrom, 2000). In the standard marking paradigm, the prioritization of new objects could potentially result from attentional capture by abrupt luminance changes as well as by top-down expectation of luminance changes. If this is the case, these factors may have additive effects on the increased efficiency of visual search for a target known to be among new, abrupt-onset objects.

Finally, given the supposed goal-relevant intentionality of marking, it may be informative to investigate observers' abilities to intentionally prioritize old objects so that they are searched before new objects. Observers should be able to search old objects efficiently when they know the old objects form the target-relevant group if, during visual marking, old and new objects are first parsed into two groups, and then one of the two groups is independently selected or prioritized for search. If marking is a voluntary, goal-directed process, an observer should be able to selectively inhibit new objects, selectively search old objects on the basis of a shared feature of the old objects, or improve visual search performance with some combination of the two.

The purpose of the present work was to investigate the relative contributions of goal-directed and stimulusdriven processes to the phenomenon of visual marking. To 
this end, we manipulated the goal state and stimulus properties on which visual marking seems to be contingent. Two experiments were conducted to examine the ability of observers to increase the efficiency of search by marking (deprioritizing) old objects, as well as their ability to avoid marking old objects in experimental conditions in which it would be beneficial to do so. In both experiments, novel conditions were included, in which the target appeared at old locations after the gap (by changing an old object into a target). In some conditions, the observers knew of this beforehand, and thus were given the opportunity to intentionally prioritize search for old objects to the extent possible. In other conditions, the target could appear unpredictably at either new or old locations. To examine the contribution of luminance increments due to new objects, the first experiment included luminanceincrements (abrupt onset of new objects) after the gap, as in typical marking experiments. In comparison, all objects (targets and distractors) in the second experiment were presented via offsets to assess the relative contribution of luminance increments associated with the onset of new objects in visual marking.

\section{EXPERIMENT 1}

In the first experiment, we examined the participants' abilities to mark either old or new objects using the standard marking paradigm. The task of the participants was to search for a target letter $(\mathrm{H})$ among distractor letters (A). A total of four blocks of trials was presented. A standard visual search block was included as a metric by which to compare marking performance. Efficient marking in this task would be manifested if search rates during the gap conditions were similar to search rates of a half baseline, in which only the new objects were presented. Inefficient marking would result in search rates comparable to the full-baseline rates, in which all of the old and new objects are presented without the temporal gap.

There were three blocks of trials with a temporal gap between the first and second sets of stimuli. In the standard marking block, the target always appeared with the set of new objects displayed in new locations after the gap. In the old-location block, the target always appeared after the gap, but at an old location that had been occupied by a distractor prior to the gap (i.e., the top line segment of an old distractor $\mathrm{A}$ was offset so that the target $\mathrm{H}$ was revealed). Finally, an intermediate mixed-block condition was included, in which the location of the target varied from trial to trial within the block. In some trials, the target appeared at a new location; on other trials, the target appeared at an old location.

If visual marking is in fact a resource-demanding, voluntary process used to deprioritize old objects during visual search, new objects should be searched at the same rate as the half baseline (i.e., when only half as many objects are searched), as is typically found. However, if it is known a priori that the target will not be found among the new objects, old locations should not be marked. Conse- quently, search rates for targets in old locations should be comparable to those of the full-baseline condition (i.e., when all objects are searched). Alternatively, if prioritization is under the complete control of the observer, it may be possible for the observer to temporally segregate and then selectively inhibit new objects as well. If this is the case, targets in the old-location condition should also be searched for at the same rate as those in the half-baseline condition, given the prior knowledge of which set of stimuli will hold the target. In the mixed block, the participants should not mark old or new objects, since to do so would result in a performance cost on half the trials. Thus, search speed in the mixed block should be equivalent to that of the full baseline, regardless of whether the target appeared at a new or an old location.

If marking is a completely automatic process that inhibits old information, search for targets in new locations should be more efficient, regardless of whether or not the participant knows which stimulus group includes the target. Similarly, search for targets in old locations should take more time than search for targets in the full-baseline condition, since the old locations will have been initially deprioritized.

\section{Method}

Participants. Eighteen undergraduates at the University of Kansas participated in the study to fulfill a course requirement. The data from two participants with error rates greater than $10 \%$ were not included in the analyses. All the participants reported normal or corrected-tonormal vision.

Apparatus. The stimuli were presented using a PowerMacintosh G3 computer. The participants were tested individually in a dimly lit room while seated in front of the monitor at a viewing distance of $50 \mathrm{~cm}$. All trials began with a centrally located gray fixation cross $\left(0.29^{\circ} \times 0.29^{\circ}\right)$, which appeared $1 \mathrm{sec}$ prior to the trial stimuli and remained present until the participant responded. The stimuli consisted of white, seven-segment capital letters displayed on a black background. The letters $\left(0.57^{\circ} \times 0.57^{\circ}\right)$ were nonoverlapping and randomly positioned within a visual field of $23.9^{\circ} \times 18.2^{\circ}$. In all trials, the distractor stimuli were the letter $\mathrm{A}$, and the target stimulus, present in $50 \%$ of the trials, was the letter $\mathrm{H}$. Trials were presented in one block for the two baseline conditions, in which all stimuli were presented simultaneously.

In the full-baseline condition, search times for 10, 20, or 30 elements were measured, whereas in the half-baseline condition search times for 5,10 , or 15 elements were measured. Thus, in the baseline conditions, target-absent trials consisted of displays of 5, 10, 15, 20, or 30 distractors; the displays for target-present trials included 4, 9, 14,19 , or 29 distractors and one target. In each of the four gap conditions, we manipulated total set sizes of 10,20 , and 30 letters by trial. After the fixation cross had been displayed for $1 \mathrm{sec}$, the first group of stimuli $(5,10$, or 15 objects) was displayed. After the temporal gap of $1,000 \mathrm{msec}$, the second group of stimuli $(5,10$, or 15 objects) was added to the display. Thus, for each trial, an equal number of old and new objects were presented.

Design and Procedure. The design included six main conditions: half baseline, full baseline, target at new location after the gap (standard visual marking paradigm), target at old location after the gap, and target randomly displayed at mixed new locations and at mixed old locations after the gap. These conditions were presented in four blocks of 180 trials each. Block order presentation was counterbalanced across participants. The full- and half-baseline conditions were included together in one block of trials, and the mixed new and 
mixed old trials were included together in another block of pseudorandomly ordered trials in which the target, when present, could occur in a new location or in an old location previously occupied by a distractor A. A third block consisted of trials in which the target, when present, always occurred in a new location. The fourth block consisted of trials in which the target, when present, always occurred at an old location simultaneously with the second group of stimuli through a change of the distractor to a target (i.e., the top bar of a distractor A was removed, changing the distractor to the target $\mathrm{H}$ ).

At the start of each block, explicit instructions regarding the expected target location for the entirety of that block were displayed on the monitor. The participants were asked to keep their eyes on the fixation cross during the temporal gap, which occurred after only the first group of objects had been displayed, and to begin their visual search after the second group of stimuli had been added to the display. Their task was to determine whether the target was present or absent in each trial. The search strategy that would be most efficient for each block was explicitly discussed with the participants while the task procedure was being explained to them (e.g., for the $100 \%$ old-location block, the participants were told that it would be most advantageous to restrict their search to the old objects). In each block, data collection began after the participants had completed 20 unrecorded practice trials. Between blocks, the participants could take self-timed breaks. Within each block, set size and target-present or target-absent trials were displayed in pseudorandom order. Response keys were the " $z$ " and the "/" keys on a computer keyboard, counterbalanced across participants.

General analytic strategy. In these experiments, the mean error rates were generally low (below 5\%) and either the overall pattern was not significant or the error rates matched the pattern of response time (RT) data, so they were not analyzed further. As with most studies of marking, only analyses of the target-present data were con- ducted further. These analyses took two forms. The first form is the standard test of differences in slopes. Marking can be assessed by a comparison of critical conditions versus the half baseline, the full baseline, or both. Slopes and RTs closer to the half baseline represent a benefit in terms of per-object search times, relative to search through a complete display. Costs are indicated by slopes that are steeper than those of the full-baseline condition or by longer RTs than in the full-baseline condition.

In the present experiments, slopes are compared using two-way analyses of variance (ANOVAs) of condition $\times$ set size, where an interaction indicates a difference in slope. In some cases, as has been pointed out by Jiang, Chun, and Marks (2002a), slopes may be equivalent even when overall RT differences can be found between conditions, indicating a preview or marking benefit. In numerous experiments, these authors failed to find reliable slope differences, although they did observe overall RT differences between conditions, indicating a benefit for preview. Jiang et al. (2002a) showed that the lack of reliable slope effects may be a due to a lack of practice and the use of large set sizes, and they suggest that analyzing both slopes and overall RT differences between conditions provides a more thorough test of the presence of marking. To this end, we provide both an analysis of overall RTs along with the analysis of slopes.

\section{Results}

All correct RTs were first subjected to a three-way trial type $\times$ condition $X$ set size ANOVA. In the mixed block, data from trials in which the target was in the new location versus data from those in which it was in the old location were analyzed as data from separate conditions. Outliers, identified as RTs of less than $250 \mathrm{msec}$, greater than
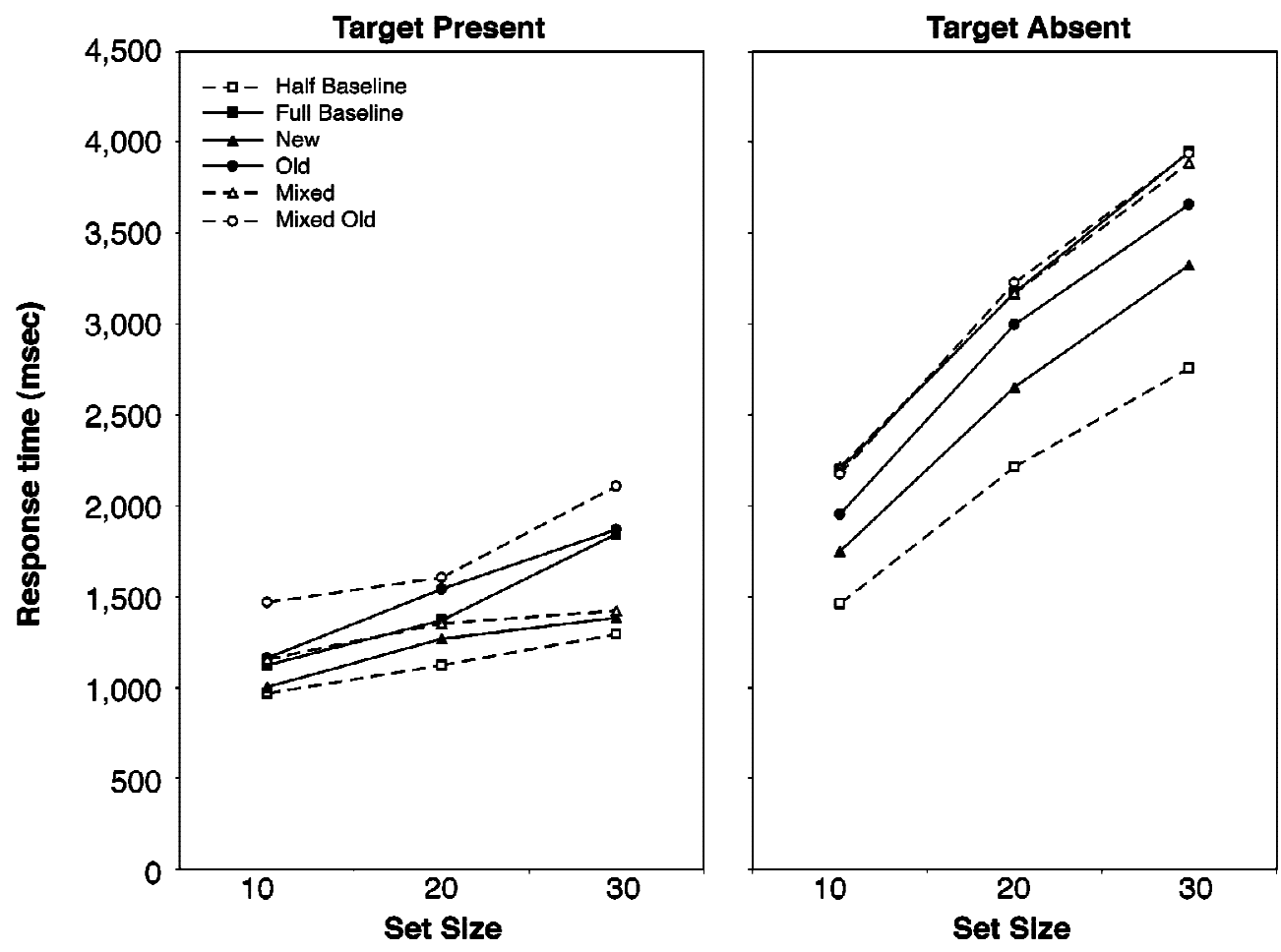

Figure 1. Average response time per condition by set size for target-present and target-absent trials in Experiment 1. 
8,000 msec, or longer than twice the RT of the individual participant's appropriate cell mean, were removed from the RT data prior to all analyses reported here, resulting in a loss of $2.7 \%$ of the trials.

The RT data are plotted in Figure 1. The results of the ANOVAs indicated significant $(p<.05)$ main effects for trial type $\left[F(1,15)=130.92, M S_{\mathrm{e}}=223,5916\right]$, condition $\left[F(5,75)=16.75, M S_{\mathrm{e}}=469,738.6\right]$, and set size $[F(2,30)=$ 101.07, $\left.M S_{\mathrm{e}}=543,743.6\right]$. All two-way interactionstrial type $\times$ condition $\left[F(5,75)=9.79, M S_{\mathrm{e}}=177,259.9\right]$, trial type $\times$ set size $\left[F(2,30)=50.65, M S_{\mathrm{e}}=305,785.4\right]$, and condition $\times$ set size $\left[F(10,150)=3.54, M S_{\mathrm{e}}=\right.$ 76,009.5] — were also significant. The three-way interaction was not significant $(F<1.5)$.

Analysis of the slope data was performed with two-way ANOVAs $(d f=2,30$; see Table 1$)$. Slopes in the halfbaseline condition (16 msec/item) were significantly shallower than slopes in the full-baseline condition $(37 \mathrm{msec} /$ item, $\left.F=6.68, M S_{\mathrm{e}}=52,161.2\right)$ and the old-location condition (36 msec/item, $F=7.17, M S_{\mathrm{e}}=41,541.8$ ). Comparison of the half-baseline condition with the mixed old condition (31 msec/item) was not significant $(F=2.26, p<$ .12). Slopes in the full-baseline condition ( $37 \mathrm{msec} /$ item) were significantly steeper than those in the new condition (20 msec/item, $\left.F=5.34, M S_{\mathrm{e}}=615,46.1\right)$ and the mixed new condition ( $16 \mathrm{msec} /$ item, $\left.F=5.19, M S_{\mathrm{e}}=94,538.3\right)$. None of the other comparisons of slope was significantly different (new vs. mixed new, $F=0.42$; old vs. mixed old, $F=1.55$; mixed new vs. mixed old, $F=2.29$ ).

Analysis of the mean RTs for the target-present data was performed using univariate ANOVAs $(d f=1,15)$. Overall RTs in the half-baseline condition (mean RT = $1,128 \mathrm{msec}$ ) were shorter than those in the full-baseline condition (mean RT $=1,445 \mathrm{msec} ; F=23.97 ; M S_{\mathrm{e}}=$ 101,213.2), the old condition (mean RT $=1,523 \mathrm{msec}$; $\left.F=50.15, M S_{\mathrm{e}}=74,688.9\right)$, the mixed new condition (mean RT $\left.=1,309 \mathrm{msec} ; F=10.52, M S_{\mathrm{e}}=74,875.9\right)$, and the mixed old condition (mean RT $=1,727 \mathrm{msec} ; F=$ $41.99, M S_{\mathrm{e}}=205,202.5$ ). RTs in the full-baseline condition were significantly longer than those in the new condition (mean RT $=1,217 \mathrm{msec} ; F=20.16, M S_{\mathrm{e}}=62,236.8$ ).
The difference between the full-baseline and the mixed new conditions was not significant $(F=3.47, p<.09)$. RTs in the full-baseline condition were significantly shorter than those in the mixed old condition $\left(F=10.41, M S_{\mathrm{e}}=\right.$ 182,281.2). Additional analyses revealed that RTs in the mixed old condition were significantly longer than RTs in the mixed new condition $\left(F=31.45, M S_{\mathrm{e}}=133,327.9\right)$ and marginally longer than RTs in the old condition $(F=$ $\left.4.25, M S_{\mathrm{e}}=235,149.7, p<.06\right)$.

\section{Discussion}

The results of Experiment 1 demonstrate the standard marking effect, such that when the target appeared at a new location (after a temporal gap), the participants were faster at detecting it than when they searched the entire set of objects. This visual marking effect occurred when they searched both for targets always occurring at new locations (search slopes and RTs were equal to the half-baseline case) and for targets at new locations in the mixed block (search slopes were equal to the half-baseline case), although in the latter case there was a cost to overall RT for doing so (mixed new RTs were greater than half-baseline RTs).

The question of interest, however, was to what degree the participants could refrain from marking old objects when it would not be beneficial. In Experiment 1, two unique conditions, in which the target appeared at an old location, addressed this question. In the mixed old condition, the target appeared at old locations randomly, so intentionally avoiding marking old objects would have been the best strategy. Yet the participants showed a significant RT cost, suggesting that objects at the old locations were still deprioritized. In the old-location condition, the participants knew that the target would always appear at an old location. Therefore, the best strategy should have been to avoid inhibiting old locations and, if possible, to prioritize old locations. In this condition, the participants did not show a significant RT cost, as they had in the mixed old condition, suggesting that they were able, to some degree, not to deprioritize old locations. No benefit for search slopes was found in this condition, however, sug-

Table 1

Search Slope Statistics by Condition in Experiment 1

\begin{tabular}{|c|c|c|c|c|c|}
\hline Con & dition & Slope (msec) & Intercept (msec) & $R^{2}$ & Absent:Present Ratio \\
\hline Half baseline & $\begin{array}{l}\text { Target present } \\
\text { Target absent }\end{array}$ & $\begin{array}{l}16.1 \\
65.0\end{array}$ & $\begin{array}{l}812 \\
844\end{array}$ & $\begin{array}{l}.999 \\
.993\end{array}$ & 4.03 \\
\hline New location & $\begin{array}{l}\text { Target present } \\
\text { Target absent }\end{array}$ & $\begin{array}{l}20.0 \\
76.2\end{array}$ & $\begin{array}{r}807 \\
1,015\end{array}$ & $\begin{array}{l}.937 \\
.988\end{array}$ & 3.81 \\
\hline Old location & $\begin{array}{l}\text { Target present } \\
\text { Target absent }\end{array}$ & $\begin{array}{l}36.0 \\
84.8\end{array}$ & $\begin{array}{r}802 \\
1,162\end{array}$ & $\begin{array}{l}.999 \\
.979\end{array}$ & 2.36 \\
\hline Mixed new & $\begin{array}{l}\text { Target present } \\
\text { Target absent }\end{array}$ & $\begin{array}{l}16.1 \\
77.0\end{array}$ & $\begin{array}{r}974 \\
1,510\end{array}$ & $\begin{array}{l}.942 \\
.975\end{array}$ & 4.78 \\
\hline Mixed old & $\begin{array}{l}\text { Target present } \\
\text { Target absent }\end{array}$ & $\begin{array}{l}30.6 \\
87.5\end{array}$ & $\begin{array}{l}1,086 \\
1,339\end{array}$ & $\begin{array}{l}.924 \\
.989\end{array}$ & 2.86 \\
\hline Full baseline & $\begin{array}{l}\text { Target present } \\
\text { Target absent }\end{array}$ & $\begin{array}{l}36.7 \\
86.0 \\
\end{array}$ & $\begin{array}{r}719 \\
1,383 \\
\end{array}$ & $\begin{array}{l}.964 \\
.995 \\
\end{array}$ & 2.34 \\
\hline
\end{tabular}


gesting that the participants were not able to selectively prioritize objects at old locations and/or deprioritize objects at new locations.

Therefore, it appears from the present data that marking, to some degree, is under the control of the observer, although it does not appear that observers can deprioritize new objects, given that the participants failed to show any benefit in the old-location condition. However, there are components of the data that suggest that there may be more to visual marking than just the deprioritization of old objects. Consider the data from the mixed condition, in which the participant could not predict if the target would be at a new or an old location. The best strategy would have been to search all objects equivalently, yet costs to overall RTs were still observed when the target appeared at an old location, and benefits to search slopes were observed when the target appeared at a new location. This result suggests that objects at new locations may have some inherent priority over objects at old locations, even when such prioritization would not be useful. This suggestion is consistent with the suggestion by Donk and Theeuwes (2001) that visual marking may be enhanced by automatic prioritization of new objects, rather than by deprioritization of old objects.

Yet the results of Experiment 1 also suggest that it is unlikely that marking is due entirely to the automatic selective prioritization of new objects. If it were, then significant costs should have been observed in the old-location condition, as they were in the mixed old-location condition, given that the new objects should have been selectively prioritized in both conditions. The results suggest that, although onsets may play some role in marking, there are additional processes, such as deprioritization of old objects, that may occur as well. A second experiment was conducted, in which the effect of onsets was eliminated to examine this issue.

\section{EXPERIMENT 2}

The purpose of the second experiment was to control for the effect of abrupt onset of the new objects on visual marking by presenting figure-eight markers at all object locations at the start of each trial. All targets and distractors were revealed via offsets of line segments from the figure-eight markers. If marking is a goal-directed process of deprioritization of unchanged objects at old locations and is not simply due to the automatic prioritization of new objects that appear via onsets, then performance benefits relative to the half baseline for targets at new locations should still be found even in the absence of abrupt onset. This hypothesis would be supported if costs are found for targets at old locations in the absence of onsets at new locations. In the second experiment, we also examined the hypothesis that the process of deprioritizing old objects is automatic. In the previous experiment, there was a cost of detecting targets at old locations when observers were unable to predict that targets would appear at old locations on every trial. A similar cost here would re- flect an automatic deprioritization of old objects, since the best strategy in this condition is to not deprioritize any objects.

\section{Method \\ Participants. Eighteen undergraduates at the University of Kansas participated in the study to fulfill a course requirement. The data from two participants with error rates greater than $10 \%$ were not included in the analyses. All the participants reported normal or corrected-to- normal vision.}

Apparatus. The apparatus was the same as in Experiment 1.

Design and Procedure. The design and procedure were similar to those of Experiment 1. However, in Experiment 2, the possible locations of the target (when present) and all distractors were occupied by figure-eight placeholders for $1,000 \mathrm{msec}$ at the start of every trial along with a centrally located gray fixation cross. Targets and distractors were displayed by removing segments of the figure-eight stimuli to produce the target $(\mathrm{H})$ and the distractors (A). As in Experiment 1 , when targets appeared at old locations, a segment from an extant $\mathrm{A}$ was removed to create the target $\mathrm{H}$. The same conditions (half baseline, full baseline, new location, old location, mixed new, and mixed old) were presented as in Experiment 1.

\section{Results}

All correct RTs were first subjected to a three-way trial type $\times$ condition $\times$ set size ANOVA. In the mixed block, data from trials in which the target was in the new location versus data from those in which it was in the old location were analyzed as data from separate conditions. Prior to the analyses reported here, outliers were removed from the RT data as in Experiment 1, resulting in a loss of $3.1 \%$ of the trials.

The RT data are plotted in Figure 2. The results of the ANOVAs indicated significant $(p<.05)$ main effects for trial type $\left[F(1,15)=20.09, M S_{\mathrm{e}}=7,674,948\right]$, condition $\left[F(5,75)=18.87, M S_{\mathrm{e}}=293,128.3\right]$, and set size $\left[F(2,30)=119.88, M S_{\mathrm{e}}=280,348.8\right]$. The two-way interaction of trial type $\times$ set size was also significant $\left[F(2,30)=10.21, M S_{\mathrm{e}}=572,149.9\right]$. No other interactions were significant.

The slope data for target-present trials were submitted to two-way ANOVAs of condition $\times$ set size $(d f=2,30$; see Table 2). As the data presented in the table reveal, the slope for the full-baseline condition is shallow $(18 \mathrm{msec} /$ item, or about half of the slope in the same condition in Experiment 1), because of very fast search speeds in the largest set size, which produced a flat search slope between the set sizes of 20 and $30\left(F=0.07, M S_{\mathrm{e}}=\right.$ $108,029.7)$. No significant effects were found in the analysis of slopes.

Analysis of the RT condition means for the targetpresent trials was performed using univariate $F$ tests $[F(1,15)]$. Overall RTs in the half-baseline condition (mean RT $=1,095 \mathrm{msec}$ ) were shorter than those in the full-baseline condition (mean RT $=1,423 \mathrm{msec} ; F=$ 9.37, $M S_{\mathrm{e}}=275,560.6$ ), the new condition (mean $\mathrm{RT}=$ $1,400 \mathrm{msec} ; F=16.63, M S_{\mathrm{e}}=134,334.5$ ), the old condition (mean RT $=1,623 \mathrm{msec} ; F=9.55, M S_{\mathrm{e}}=700,837.0$ ), the mixed new condition (mean RT $=1,592 \mathrm{msec} ; F=$ $\left.13.45, M S_{\mathrm{e}}=441,835.5\right)$, and the mixed old condition 

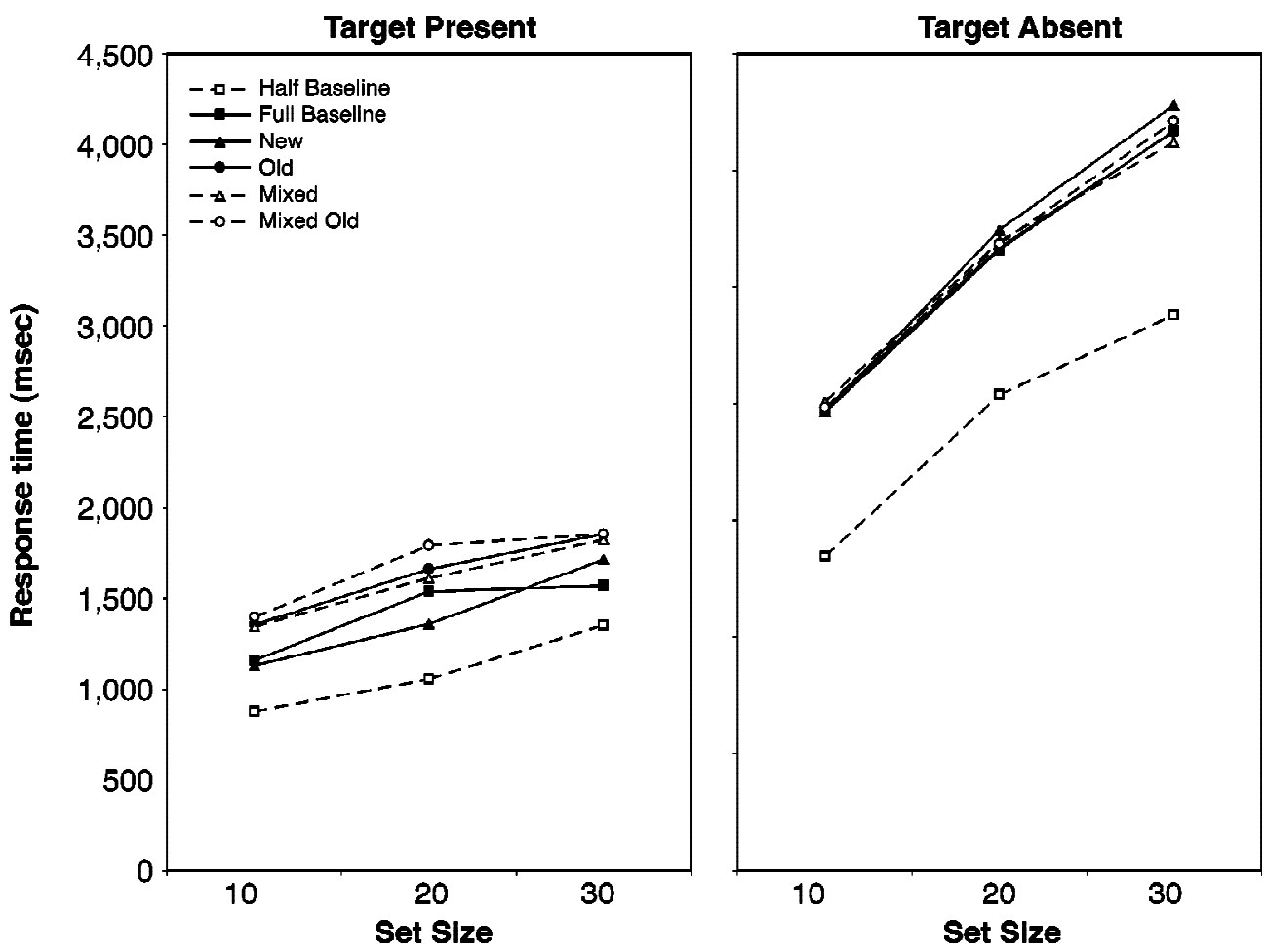

Figure 2. Average response time per condition by set size for target-present and target-absent trials in Experiment 2.

(mean RT $=1,680 \mathrm{msec} ; F=20.08, M S_{\mathrm{e}}=409,632.6$ ). RTs in the full-baseline condition were marginally shorter than those in the mixed old condition $\left(F=3.54, M S_{\mathrm{e}}=\right.$ $449,947, p<.07)$. Additional analyses revealed that RTs in the mixed old condition were significantly longer than RTs in the mixed new condition $\left(F=4.88, M S_{\mathrm{e}}=37,875.2\right)$ and marginally longer than RTs in the new condition $(F=$ $\left.3.85, M S_{\mathrm{e}}=222,574.1, p<.07\right)$.

\section{Discussion}

The results of Experiment 2 do not indicate that the participants were able to use visual marking to aid search in the absence of abrupt onsets, as is evidenced by both the RT and the search slope data. The search slope data failed to reveal any differences. Search slopes for the full-baseline condition were abnormally shallow as compared with those of Experiment 1 and previous work. This effect was primarily due to the fact that very short RTs in the largest set size condition produced near-zero search slopes between the intermediate and the largest set sizes. This is not itself problematic, because marking can be revealed by a comparison with the slope data of the half-baseline condition. ${ }^{1}$ The half-baseline slope data were similar to the corresponding data from the first experiment. In the ab-

Table 2

Search Slope Statistics by Condition in Experiment 1

\begin{tabular}{|c|c|c|c|c|c|}
\hline \multicolumn{2}{|c|}{ Condition } & Slope (msec) & Intercept (msec) & $R^{2}$ & Absent:Present Ratio \\
\hline Half baseline & $\begin{array}{l}\text { Target present } \\
\text { Target absent }\end{array}$ & $\begin{array}{l}18.1 \\
58.9\end{array}$ & $\begin{array}{l}694 \\
791\end{array}$ & $\begin{array}{r}1.000 \\
.990\end{array}$ & 3.25 \\
\hline New location & $\begin{array}{l}\text { Target present } \\
\text { Target absent }\end{array}$ & $\begin{array}{l}23.2 \\
71.0\end{array}$ & $\begin{array}{r}804 \\
1,330\end{array}$ & $\begin{array}{l}.996 \\
.984\end{array}$ & 3.06 \\
\hline Old location & $\begin{array}{l}\text { Target present } \\
\text { Target absent }\end{array}$ & $\begin{array}{l}24.1 \\
71.5\end{array}$ & $\begin{array}{r}854 \\
1,460\end{array}$ & $\begin{array}{l}.995 \\
.989\end{array}$ & 2.97 \\
\hline Mixed new & $\begin{array}{l}\text { Target present } \\
\text { Target absent }\end{array}$ & $\begin{array}{l}28.3 \\
64.6\end{array}$ & $\begin{array}{r}793 \\
1,542\end{array}$ & $\begin{array}{l}.986 \\
.960\end{array}$ & 2.28 \\
\hline Mixed old & $\begin{array}{l}\text { Target present } \\
\text { Target absent }\end{array}$ & $\begin{array}{l}24.9 \\
70.3\end{array}$ & $\begin{array}{r}975 \\
1,428\end{array}$ & $\begin{array}{l}.999 \\
.985\end{array}$ & 2.82 \\
\hline Full baseline & $\begin{array}{l}\text { Target present } \\
\text { Target absent }\end{array}$ & $\begin{array}{l}18.0 \\
64.7\end{array}$ & $\begin{array}{r}915 \\
1,437\end{array}$ & $\begin{array}{l}.867 \\
.983\end{array}$ & 3.59 \\
\hline
\end{tabular}


sence of onsets at new target locations as in Experiment 1, search slopes for targets at new and old locations (in both the $100 \%$ valid block and the mixed block) were similar to each other and to those in the full-baseline condition. This pattern of results is consistent with a role for onsets on the marking effect (Donk \& Theeuwes, 2001). As will be discussed next, this pattern of data also indicates, in consistency with the conclusion of Jiang et al. (2002a), that overall RT data can be a useful source of information in the absence of compelling slope data.

In Experiment 2, the half-baseline condition produced significantly shorter RTs relative to all other conditions. Although there was no effect on search slopes, the presence of elevated RTs in the other conditions relative to the half-baseline condition is consistent with the presence of more exhaustive search through a larger set of objects. Evidence of marking was found in the form of a cost in terms of longer overall RTs for the mixed old-location condition (in which the target was revealed at the location of an old distractor) in comparison with RTs in the full-baseline condition. The pattern of cost at old locations was also seen in comparison with search at new locations in the new-location block and on mixed new-location trials. In previous marking experiments, search was faster when targets were anticipated to appear at locations after the temporal gap in comparison with the baseline condition, when all objects (target and distractors) were presented simultaneously. However, in the present experiment, when onsets were eliminated as a feature of new objects (i.e., objects after the gap), the typical marking effect was not observed. When the target was presented at a figure-eight location after the gap, the time needed to detect the target was the same as when the target and distractors were presented simultaneously.

These results are consistent with the work of Donk and Theeuwes (2001), which suggests that the marking effect is due to a prioritization of objects at new locations when those objects appear via increases in luminance. In their experiments, objects presented after the gap were equiluminant to the background, thereby eliminating increases in luminance associated with new objects. In the present experiment, we controlled for the effect of increased luminance at new locations after the gap by presenting stimuli to serve as placeholders at those locations and removing line segments from the placeholders to produce the target and distractors. In the absence of a salient perceptual event such as the abrupt onset of the new objects, neither experiment produced evidence of marking.

Recently, Watson and Humphreys (2000) reported evidence of marking at old locations by demonstrating inhibition via a probe dot at old locations. Such inhibition would presumably lead to an increase in RT to a target at that location under the present conditions. In the present experiment, evidence of this inhibitory effect was found when targets appeared at old locations on random trials during a block. We did not find evidence of inhibition at old locations when the target appeared at old locations on every trial. Therefore, although the present results are consistent with those of Donk and Theeuwes (2001) in that marking is related to the influence of onsets at new locations, it also appears that inhibition of old locations occurs as well (to some degree under voluntary control), in accordance with Watson and Humphreys (2000).

\section{GENERAL DISCUSSION}

Two experiments were conducted to examine the degree to which marking is under the conscious control of the observer versus the extent to which stimulus-driven, automatic processes contribute to visual marking. It can be argued that the best deprioritization mechanism would be one that is under the control of the observer, given various search conditions. Although the benefit of selectively monitoring new information is readily imaginable, one can also envision instances in which it would be most efficient to search only through old information while ignoring new information. For example, imagine that you arrive at a busy restaurant and begin searching the diners for a friend that you expect to meet for lunch. You search the restaurant and do not find your friend. You briefly glance at the hostess to get her attention, and a number of new people come in and take seats. If you are certain that your friend was not in the first group, you might then try to search only the new people, as a way of increasing your search efficiency. However, imagine weather conditions require people to wear additional clothing, which prevents you from being certain that your friend was not among the first group of patrons, but, rather, may have simply been bundled up against the cold. During the interval in which the new patrons arrived, your friend may have revealed him or herself, and would thus be a target in the old group. In this case, it would be inefficient to deprioritize the old group. In fact, it might be most efficient to deprioritize only the new diners, if you knew that they did not include your dining companion.

In the present experiments, an attempt was made to replicate these situations. In both experiments, when the participants knew that the target would appear at an old location, search efficiency was equivalent to that in the fullbaseline condition. The lack of a difference in mean RT or search slopes between the full-baseline and old-location conditions shows that the participants did not demonstrate a benefit in performance even though they had accurate, target-relevant information. We cannot infer from these results if the participants simply did nothing (i.e., searched for the target at all locations), since the target-relevant information did not indicate that they could mark old objects, or if they allocated resources to intentionally refrain from marking the old objects. A third possible alternative might be that the participants were in fact able to intentionally prioritize the first group of stimuli, but, after the luminance change due to the presentation of the second group of stimuli, the potential benefit of intentionally selecting the old objects was less than the cost of resources required to inhibit the new objects.

Though it would appear that the participants chose not to mark the target-relevant old objects, this inference must be modified on the basis of the data obtained from the 
mixed block of trials, in which the target could appear at old locations or new locations and the participants were told that the location of the target would be randomly distributed between old and new locations. The best strategy in this case would have been to avoid intentionally deprioritizing or prioritizing either the old or the new location, since, in the absence of target-relevant information, preferentially searching either group of objects would be detrimental on approximately half of the trials. In both experiments, however, the participants were slower to detect the target (relative to the full-baseline condition) when it appeared at an old target location. Yet they were not slower to detect the target when it appeared at a new location in the mixed block. In fact, in the first experiment, in which the objects were presented via luminance increments at previously unoccupied locations, the participants detected the target more rapidly than in the full-baseline condition. This effect was not found in the second experiment when onsets were eliminated, which suggests that it may be due to the ability of new objects and their accompanying luminance increments to automatically attract attention (see, e.g., Yantis, 1996).

The difference between new and old target locations across $100 \%$ valid and mixed blocks is illustrated in Figure 3, which presents the Vincentized RT distributions for targets appearing at new or old locations in these two types of trials. In Vincent averaging (Ratcliff, 1979), distributions of RT data are normalized across participants. This provides some insight into the basis for differences in overall RT data across these conditions. One aspect of the data for Experiment 1 is that the shortest RTs are gener- ally similar across conditions, indicating that on some subset of the trials across all conditions, the participants were able to detect the target rapidly. Thus, even if new objects were prioritized due to onsets, the participants were able to overcome this effect on some trials to detect targets at old locations efficiently. However, objects at new locations clearly had an advantage across the full range of RTs. RTs for targets at old locations were generally much longer than new-location RTs, with approximately $20 \%$ of the old-location RTs exceeding the longest of the newlocation RTs. In addition, RTs for targets at new locations seem to be relatively unaffected by whether or not the block is mixed. This effect supports the notion that some priority is given to new objects defined by onsets, regardless of whether or not the onsets help to predict the target location. In comparison, RTs for targets at old locations appear to benefit from whether or not the participants knew that targets would appear at old locations. Across the full range of RTs, the participants' RTs were longer for targets appearing at old locations in the mixed block.

The RT distributions for Experiment 2 do not provide the same distinctions. In the absence of onsets, new- and old-location RTs were similar. The old-location distributions were similar in Experiments 1 and 2 because, in both cases, the participants were required to detect targets at locations that had previously contained a placeholder. What appeared to happen was that the RT distribution for newlocation conditions shifted toward increasingly longer RTs, much like the old-location distributions, since targets at these locations also had previously contained a placeholder.
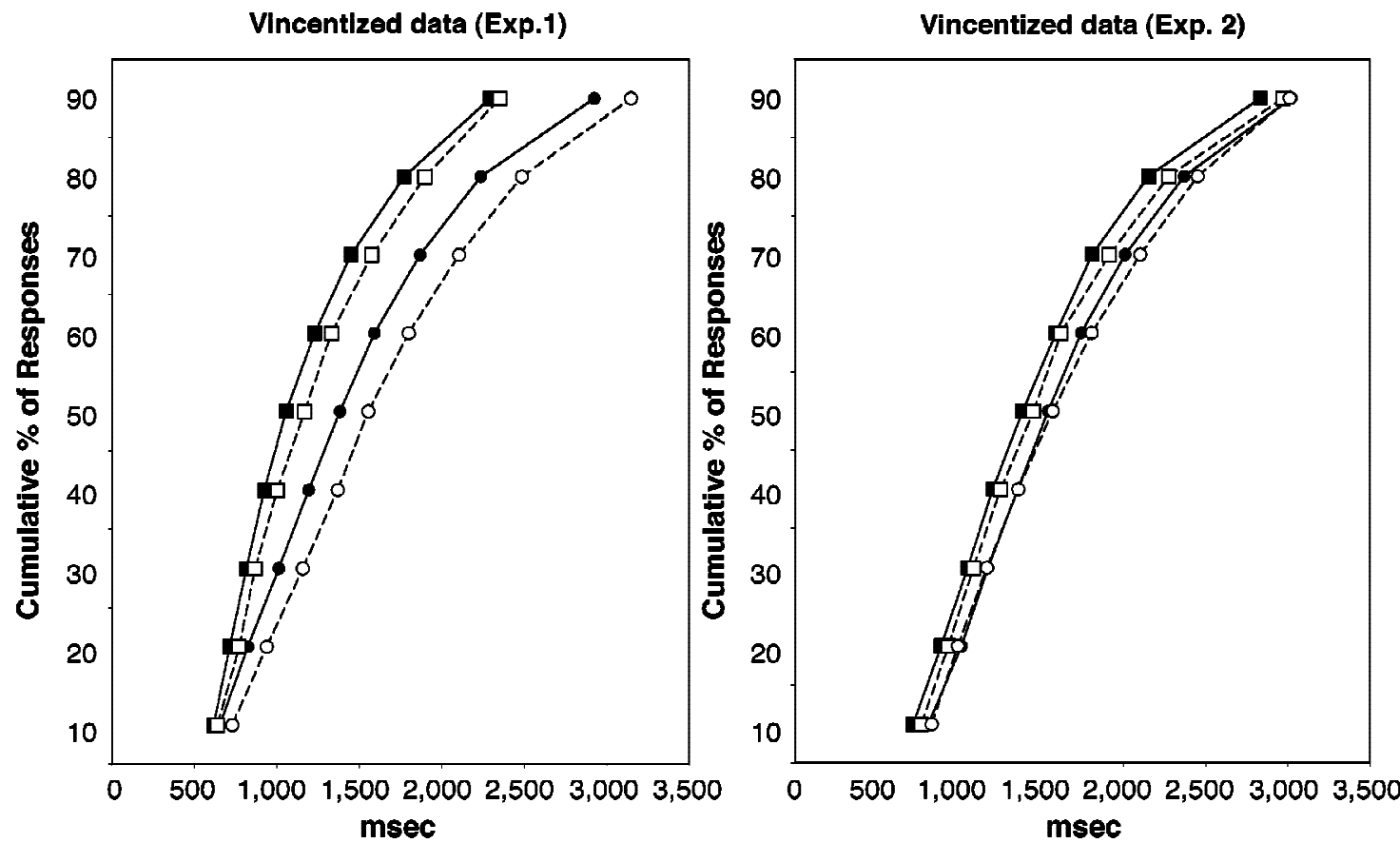

Figure 3. Vincentized data for new and old conditions in Experiments 1 and 2. Squares: new location; circles: old location; filled symbols, solid line: standard block; open symbols, dashed line: mixed block. 
The patterns of data from the $100 \%$ old and mixed old blocks across the two experiments suggest that deprioritization at old locations may be an automatic process of the attentional system. When the participants were certain that a target would occur at an old location, a target-relevant goal state resulted in a reduction of the deprioritization process. When the participants were uncertain regarding whether or not the target would appear at an old location, they could not have a target-relevant goal. Nevertheless, old objects continued to be deprioritized, as is illustrated by longer RTs in the mixed old condition than in the $100 \%$ old condition and by differences in the distribution of RTs in Experiment 1. Although our restaurant example illustrates that deprioritization may be costly under certain conditions, we suggest that such situations are relatively infrequent. Most of the time, when we search for and fail to find our target, the objects we have searched will not turn into the target. It is far more likely that a set of new objects will contain the target. Therefore, automatically deprioritizing old objects (whether because they have been identified as distractors, or after the passage of an amount of time during which, if present, the target would have been found) would seem to be an efficient process that could produce the fastest search in the majority of conditions.

Given the present results and the results of previous work (e.g., Donk \& Theeuwes, 2001; Watson \& Humphreys, 2000), what is visual marking? Watson and Humphreys (1997) proposed marking to be the result of an intentional deprioritization of objects at old locations, thereby enhancing the selection of objects at new locations. The results of Donk and Theeuwes's investigation suggest that visual marking may be an epiphenomenon of attentional capture by the onsets of new objects and their accompanying luminance increments. The present data suggest that both of these views have some validity. Although it does appear that with an appropriate goal state the cost of automatically marking old objects can be mitigated, it is also apparent that marking is an automatic process (i.e., marking occurs even when it produces slower search). Furthermore, it does not appear that the participants can mark or inhibit a group of new objects, which would be the best demonstration of full control over the marking process.

With regard to the contribution of onsets to the marking phenomenon, it does appear that the presence of onsets inflates the size of what could be considered marking, in accordance with the conclusions of Donk and Theeuwes (2001). In Experiment 1, a benefit (equivalent slopes for the new/mixed new and half-baseline conditions and equivalent RTs for the half-baseline and new-location conditions) was observed when objects appeared (via onsets) at new locations. This benefit was not present in the second experiment, when onsets were no longer features of new objects. The continued presence of costs for objects appearing at old locations, with or without onsets at new locations, is consistent with the conclusion of Watson and Humphreys (2000) that marking, or inhibition at old locations, does occur. The consideration of situations in which the visual marking of old objects appeared to ben- efit search (e.g., when the observer has a target-relevant goal state, when the appropriate goal requires searching new objects, and when old objects remain static and new objects include a luminance change), as well as situations in which marking apparently does not benefit search, leads to the conclusion that standard visual marking results are the likely product of voluntary processes, automatic processes, and fortuitous conditions.

To conclude, the present results reconcile previous work suggesting that marking exists as an inhibitory mechanism with work suggesting that marking is due to prioritization of new objects and their accompanying changes in luminance. The present work revealed evidence that marking does occur, at least as a deprioritization of old objects, despite the absence of onsets. The presence of onsets at new locations does increase or magnify the size of the effect, however, indicating that in previous work the benefit of marking on visual search may have been overestimated. Furthermore, these results have shown that marking is somewhat under the control of the observer, but that the deprioritization of old objects during search is also an automatic process of the visual attention system. Observers can refrain from marking old objects when they are certain a target will occur at an old location, but why they appear to inhibit old objects, relative to a temporal gap, when they are uncertain about the final target location, is unknown. In addition, observers do not seem to be able to enhance visual search by intentionally prioritizing old objects. We conclude that visual marking results from a convergence of automatic deprioritization of old objects, a voluntary top-down process that selects target-relevant luminance changes, and an intentionally adopted goal state of not searching target-irrelevant old objects. When the search environment is appropriate for these processes to complement each other, it results in significant benefits during visual search.

\section{REFERENCES}

Atchley, P., Kramer, A. F., \& Hillstrom, A. P. (2000). Contingent capture for onsets and offsets: Attentional set for perceptual transients. Journal of Experimental Psychology: Human Perception \& Performance, 26, 594-606.

Donk, M., \& Theeuwes, J. (2001). Visual marking beside the mark: Prioritizing selection by abrupt onsets. Perception \& Psychophysics, 63, 891-900

Folk, C. L., Remington, R. W., \& Johnston, J. C. (1992). Involuntary covert orienting is contingent on attentional control settings. Journal of Experimental Psychology: Human Perception \& Performance, 18, 1030-1044.

JiAng, Y., Chun, M. M., \& Marks, L. E. (2002a). Visual marking: Dissociating effects of new and old set size. Journal of Experimental Psychology: Human Perception \& Performance, 28, 293-302.

JiAng, Y., Chun, M. M., \& MARKs, L. E. (2002b). Visual marking: Selective attention to asynchronous temporal groups. Journal of Experimental Psychology: Human Perception \& Performance, 28, 717-730.

JonideS, J., \& YANTIS, S. (1988). Uniqueness of abrupt onset in capturing attention. Perception \& Psychophysics, 43, 346-354.

Kahneman, D., Treisman, A., \& Burkell, J. (1983). The cost of visual filtering. Journal of Experimental Psychology: Human Perception \& Performance, 9, 510-522.

Kramer, A. F., \& Atchley, P. (2000). Age-related effects in the visual marking of old objects. Psychology \& Aging, 15, 286-296. 
RATCLIFF, R. (1979). Group reaction time distributions and analysis of distribution statistics. Psychological Bulletin, 86, 446-461.

Theeuwes, J., Kramer, A. F., \& Atchley, P. (1998). Visual marking of old objects. Psychonomic Bulletin \& Review, 5, 130-134.

WATson, D. G. (2001). Visual marking in moving displays: Featurebased inhibition is not necessary. Perception \& Psychophysics, 63, 7484.

Watson, D. G., \& Humphreys, G. W. (1997). Visual marking: Prioritizing selection for new objects by top-down attentional inhibition of old objects. Psychological Review, 104, 90-122.

Watson, D. G., \& Humphreys, G. W. (1998). Visual marking of moving objects: A role for top-down feature-based inhibition in selection. Journal of Experimental Psychology: Human Perception \& Performance, 24, 946-962.

Watson, D. G., \& Humphreys, G. W. (2000). Visual marking: Evidence for inhibition using a probe-dot detection paradigm. Perception \& Psychophysics, 62, 471-481.

YANTIS, S. (1996). Attentional capture in vision. In A. F. Kramer, M. G. H. Coles, \& G. D. Logan (Eds.), Converging operations in the study of visual selective attention (pp. 45-76). Washington, DC: American Psychological Association.
YAntis, S., \& Jonides, J. (1984). Abrupt visual onsets and selective attention: Evidence from selective search. Journal of Experimental Psychology: Human Perception \& Performance, 10, 601-621.

\section{NOTE}

1. As with standard marking experiments, the half-baseline slope is half of the actual slope, because the half-baseline condition is plotted with data from conditions with twice its actual number of objects. This provides a measure of search through half of the objects, equal to the number of objects searched in the case of perfect marking. Data in this format is, in part, a result of covarying the number of new and old objects. Jiang et al. (2002a) suggest that old set-size slopes are a better measure of a preview benefit in marking. This value can be obtained by varying the number of new and old objects independently.

(Manuscript received February 2, 2001; revision accepted for publication November 19, 2002. 